\title{
UNA ARQUITECTURA AUSENTE ILUMINA LA CELEBRACIÓN DEL MISTERIO. LA IGLESIA DEL MONASTERIO BENEDICTINO DE LAS CONDES Entrevista al arquitecto Martín Correa, OSB.
}

\author{
Rubén Muñoz Rodríguez \\ Missing architecture lights up the celebration of Mistery. The church of the benedictine \\ monastery, Las Condes. Interview with architect Martin Correa, OSB. \\ Boletín Académico. Revista de investigación y arquitectura contemporánea \\ Escuela Técnica Superior de Arquitectura. Universidade da Coruña \\ elSSN 2173-6723 \\ unw.boletinacademico.com \\ Número 2 (2012) \\ Páginas 56-63 \\ Fecha de recepción 01.10.2011 \\ Fecha de aceptación 02.02.2012
}

https://doi.org/10.17979/bac.2012.2.0.977

\begin{abstract}
Resumen
La iglesia de Las Condes (1962/64), proyectada por los monjes benedictinos Martín Correa y Gabriel Guarda, constituye una obra paradigmática de la arquitectura latinoamericana. Ha sido la primera obra moderna declarada monumento nacional en Chile (1981), siendo recientemente galardonada con el premio "Obra Bicentenario" (2009). Desde la mirada de uno de sus autores, se exponen los temas centrales de un caso ejemplar en la comprensión arquitectónica de los requerimientos contemporáneos de la liturgia.
\end{abstract}

\begin{abstract}
Las Condes church (1962/64) was projected by benedictine monks Martín Correa and Gabriel Guarda. It is a paradigmatic work in Latin American architecture, and also the first modern building declared National Monument in Chile (1981). It has recently been awarded "Obra Bicentenario" prize (2009). Here are presented the main ideas, from the point of view of one of its authors, that leaded this work as a model for architectural comprehension of contemporary liturgy requirements.
\end{abstract}

Palabras clave

Iglesia, monasterio, Las Condes, arquitectura religiosa.

Keywords

Church, monastery, Las Condes, sacred architecture. 

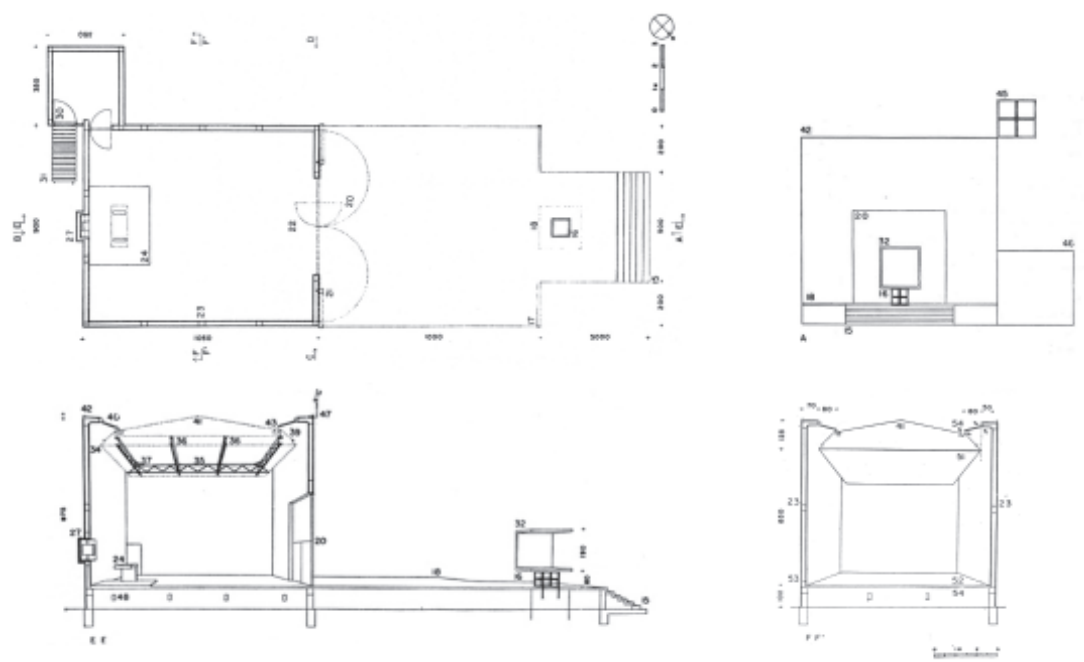

1 Alberto Cruz Covarrubias, capilla Pajaritos, Valparaíso (Chile), 1952; proyecto.

El arquitecto chileno Alberto Cruz, refiriéndose a la arquitectura sacra contemporánea, plantea:

\footnotetext{
Veía una publicación reciente de iglesias, con bastantes recursos. Están muy bien, pero no son, no alcanzan un grado de canto religioso, queda una buena composición arquitectónica, pero no lo otro... En las iglesias nunca se alcanza el asunto, en realidad son unos fracasos, por decirlo de alguna manera. Hay otras obras, las civiles, laicas, en ellas sí se alcanza. En ese sentido es muy curioso. ¿Cuál es una iglesia que en sí no ha sido un fracaso? La de los benedictinos. ¿Por qué no ha sido un fracaso? ${ }^{1}$.
}

El proyecto de la iglesia de Las Condes fue desarrollado por Martín Correa y Gabriel Guarda², con la colaboración de Patricio Gross. Siendo ya dos jóvenes monjes que habían renunciado a la profesión de arquitectos para abrazar la profesión litúrgica, aceptaron el encargo por obediencia a sus superiores. Viviendo en el mismo monasterio, su desarrollo implicó una total dedicación interior durante un periodo de dos años, conociendo desde dentro los requerimientos más sutiles del encargo. Sin embargo, dicha comprensión sólo es el principio, no bastaría para hacer una obra que - en palabras de Cruz- cante lo religioso. Sin apenas experiencia como arquitectos, los autores recogieron en esta obra una serie de propuestas y reflexiones previas, destacándose por encima de la filiación corbusiana una serie de proyectos desarrollados entre 1952 y 1960 al alero del Instituto de Arquitectura de la PUCV (Pontificia Universidad Católica de Valparaíso), en un periodo de especial efervescencia, tanto a nivel internacional como nacional, previo al Concilio Vaticano II.

Como parte de una tesis doctoral en desarrollo ${ }^{3}$, este texto es un extracto de una serie de entrevistas realizadas a Martín Correa entre 2007 y 2009 en el monasterio benedictino de la Santísima Trinidad de Las Condes de Santiago de Chile, constituyendo una fuente primaria de información sobre el caso, desde los planteamientos del principal autor del proyecto.

\section{EL ENCARGO}

Jaime Bellalta gana el concurso del monasterio, desarrolla el edificio de las celdas, se va a Inglaterra, el Instituto de Arquitectura de Valparaíso presenta un nuevo proyecto que es rechazado, y después ustedes toman el proyectó. El hecho de haber dejado la profesión para entrar en el monasterio, esa renuncia, ¿cómo le hizo enfrentar el encargo?

Me costó mucho aceptar. Por un lado, la incapacidad obvia para hacer una obra como una iglesia, la responsabilidad tremenda, ya que iba a vivir aquí el resto de mis días; y por otro lado, el temor a la crítica que se veía venir, especialmente por parte de mis colegas.

¿Qué rol cumplió cada uno? ¿Cuánto tiempo duró el desarrollo del proyecto? ¿Cómo compatibilizaron el régimen de vida benedictina mientras lo desarrollaban?

La situación era la siguiente: la concepción del proyecto fue de los dos, Gabriel y yo. Patricio Gross, recién salido de la universidad, entró a colaborar como ayudante en la ejecución de los planos y en la obra misma, aportando mucho en estas dos etapas. La etapa de la concepción y anteproyecto duraría unos seis meses, la puesta en limpio otros cuatro y la construcción un 


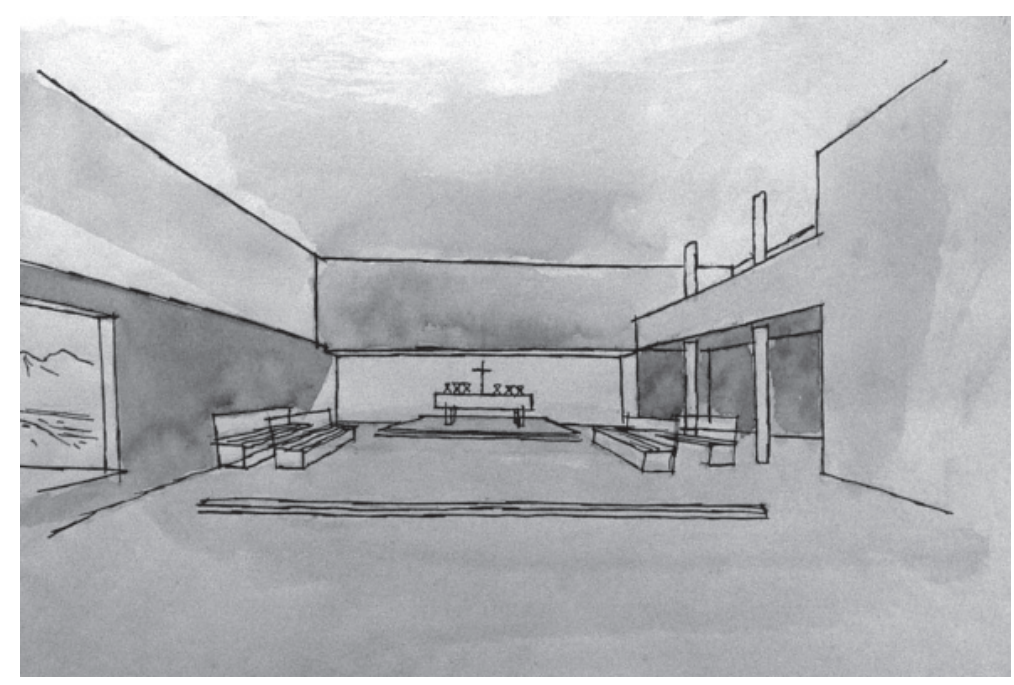

2 Jaime Bellalta Bravo, iglesia del monasterio benedictino de Santa María, Las Condes (Chile), 1953; proyecto.

año. Nuestro horario permitía unas cinco horas diarias [de trabajo], aunque bastante interrumpidas — gracias a Dios- por el Oficio Divino, nuestra oración comunitaria.

\section{PRECEDENTES}

¿Qué obras de arquitectura sacra, en Chile y en el extranjero, considera ejemplares?

Dado que soy monje benedictino desde hace más de cincuenta años, tengo que decir que, debido a mi enclaustramiento, no he viajado a Europa, y por lo tanto no puedo opinar a partir de una experiencia directa sobre las grandes obras románicas o góticas, por citar algo ejemplar. Sin embargo, como arquitectura contemporánea religiosa, la capilla de Ronchamp de Le Corbusier fue para mí una fuente de inspiración por su libertad de formas, posibles en gran parte por el uso del hormigón armado. En Chile, admiro las iglesias del Norte Grande y de Chiloé. En la capital, siento gran respeto por algunas neoclásicas, como la basílica del Salvador o la de Santa Ana, aunque casi todo ha sido copia neoclásica más o menos afortunada.

Aparece citada con frecuencia la influencia de Le Corbusier en esta iglesia. Basta la afirmación del colombiano Rogelio Salmona, quien plantea que sería "la mejor iglesia que hizo Le Corbusier". ¿Qué valores de la arquitectura moderna vieron que podian ser traspasados a la arquitectura para el programa religioso? ¿Qué influencias tendría la obra de Le Corbusier en esta iglesia?
Nosotros teníamos en casa la mejor fuente de inspiración en lo construido: el edificio de las celdas y la capilla provisoria. Para mí, la influencia de Jaime Bellalta fue fundamental. Lo único que pretendí fue dejarme guiar por la importancia que le daba a la luz, por el color blanco, por la simplicidad, por la falta de pretensión decorativa. Le Corbusier era un referente, pero en segundo plano.

Ciertamente en esa época estaba Ronchamp, la gran novedad, y yo la admiraba profundamente; admiraba la libertad de Le Corbusier para hacer eso. Me influyó como para decir no me importa que lo que uno haga no tenga mucho que ver con lo anterior. Lo importante era ser fiel a una búsqueda, elaborando [el proyecto] poco a poco a partir de las necesidades reales para esta construcción, partir de la base, de lo mínimo, creando, viendo, dando soluciones a las necesidades y que resultara lo que resultara, sin partir de una imagen preconcebida.

Con respecto al tratamiento de la luz, esta iglesia dista bastante de la obra sacra corbusierana. En Ronchamp, con sus grandes masas megaliticas suspendidas y horadadas, o en la Tourette, con sus ranuras orientadas cercanas al románico, prima una luz muy rebajada. En Las Condes, aparte de aumentar considerablemente la intensidad, aparecen los planos separados en sus aristas como pantallas de luz indirecta, una solución de algún modo más moderna. ¿Qué opina usted de la tesis de Fernando Pérez Oyarzun sobre la filiación con la capilla de Pajaritos? :Existe una relación con la luz como la planteada por Alberto Cruzs? 
Yo la conocía, pero me daba la impresión de una frialdad muy grande, no me seducía el resultado de los $\mathrm{Pa}$ jaritos, era para desanimarse (Fig. 1). Al ver ese cubo, uno decía: ¡Horror! Es indudable que está la idea de [introducir] la luz por arriba, era una cosa que había que atender, pero lo que más me influenció fue la capilla provisoria de Bellalta. Sin duda somos deudores de la capilla de los Pajaritos, pero trasvasijado a lo que hemos vivido en la obra y persona de Jaime Bellalta, al que le debo lo bueno que haya en nuestra obra.

\section{¿En qué sentido le influenció Bellalta?}

El haber vivido ya unos diez años en el cuerpo de celdas me permitió empaparme en el tratamiento del espacio, en la simplicidad y verdad de sus soluciones y en la luz como elemento capital. En cuanto a la capilla no construida (Fig. 2), el corte horizontal y el desplazamiento del muro de fondo y lateral me dieron una clave que iba mucho más allá de ese detalle y que me decía cómo enfocar el encuentro de volúmenes y espacios en general. No me es fácil explicar en palabras un asunto que es espacial: los cortes y desplazamientos de los muros me influyeron mucho; también el hecho de que no coincidieran los paralelepípedos, que estuvieran desplazados. Ese juego se me grabó como posibilidad de jugar espacialmente, de permitir una luz diferente: la luz que entra hacia abajo, diferente a la que entra hacia arriba.

Viendo ciertas características de la arquitectura moderna — su simplicidad, el vaciamiento de decoración, etc.se podrian encontrar principios retomados en el espacio religioso contemporáneo. En este sentido, aparecen otras obras cercanas, como la iglesia del Corpus de Rudolf Schwarz: ¿la conocía?

Sí, la conocía, pero como referente a evitar: la arquitectura alemana no me entraba. Yo encuentro que tiene mucha riqueza, pero me da susto por la frialdad. El desafío es cómo hacer de esto algo habitable, amistoso; el peligro es que aparezca el Dios terrible.

Muy cercana en la distribución en planta es la iglesia de Alcobendas de Fisac, en Madrid. También es una iglesia para religiosos; el padre Gabriel reconoce su influencia?.

Qué curioso, es parecida, hay una gran similitud. La angostura entre los dos espacios de los fieles y de los monjes fue un tema que me preocupó mucho: qué dimensión se le daba a esta boca, de modo que no cortara la unidad y produjera la independencia que queríamos. Yo encuentro que en el caso de Alcobendas hay demasiada estrechez, pero es muy interesante.

\section{EL PROYECTO}

Con respecto a la liturgia, a las puertas del Concilio Vaticano II, ¿cuáles fueron sus fuentes? ¿Cuáles fueron los puntos importantes que influyeron en la iglesia?

Es algo que estaba por todos lados, gracias al denominado Movimiento Litúrgico de origen benedictino ${ }^{10}$, con el abad de Solesmes, Dom Guéranger, y autores como Odo Casel o Romano Guardini, junto a numerosas revistas sobre el tema. En fin, estábamos metidos en un ambiente de gran inquietud litúrgica, se respiraba por todos lados. La centralidad, la ubicación del Santísimo, la eliminación de los altares particulares, eran un común denominador. Creo que lo más destacable era la concelebración en la Eucaristía.

Llama la atención la ausencia de imágenes, el despojamiento; algunos la asocian con un cierto aire protestante, al no seguir la línea tradicional de la Iglesia católica.

El hecho de que el Concilio permita la concelebración, con la desaparición de los altares múltiples para las misas privadas, te desnuda la iglesia. Y, después de eso, hay un cierto rechazo al exceso de esta santería, pues uno no la necesita para su piedad. Creemos que para un monasterio no hay ningún compromiso para empezar a poner devociones.

¿Cómo se afrontó en la iglesia la posibilidad de constituir un "signo y simbolo de las realidades celestiales"1?

Esto de las realidades celestiales me suena un poco vago. Jesucristo encarnó estas realidades en su persona y en su mensaje, revelándonos que nuestro destino no era para aquí, sino junto al Padre. Entonces, de lo que se trataba era de concebir una posada, una tienda para el Pueblo de Dios en camino, con una doble orientación comunitaria, para los monjes y para los fieles; un espacio donde se pueda celebrar la Eucaristía, que actualiza y hace presentes la pasión, muerte y resurrección del Señor.

\section{¿Cómo se buscó potenciar la experiencia religiosa?}

La experiencia religiosa se posibilita fundamentalmente en la oración. Procuramos crear un ambiente de recogimiento, desnudo, sin decoración, con una luminosidad muy controlada y con la centralidad del altar, símbolo de Jesucristo.

Aparecen como punto de partida las dos comunidades formando dos cuerpos, con los dos cubos que se intersectan en el altar. 


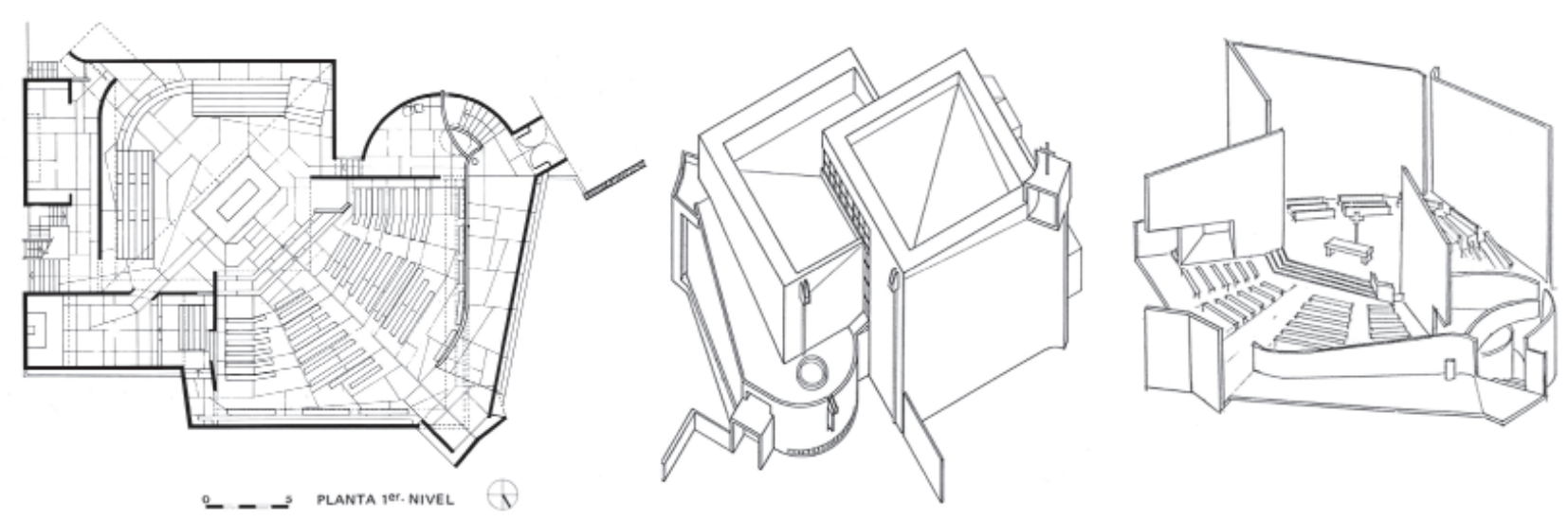

3 (De izda. a dcha.) Martín Correa Prieto y Gabriel Guarda Geywitz, iglesia del monasterio benedictino de Santa María, Las Condes (Chile), 1962/64; planta, axonometría exterior y axonometría interior.

De allí se partió. Se podría haber intentado una solución de otra manera — por ejemplo, un paralelepípedo, con los monjes y los fieles en cada extremo y el altar al medio-, pero nos dimos cuenta de la importancia de conseguir una angostura necesaria para independizar los dos sectores. Podría haber sido un arco, pero algo así nos parecía artificioso. En cambio, al producir el desplazamiento de los cubos se produjo esta angostura en el encuentro, permitiendo la ubicación del altar, y al mismo tiempo, que las dos zonas fueran muy definidas en sí mismas (Fig. 3). El problema por resolver era que tal angostura no destruyera la continuidad de los dos cubos. Mi interés era que mirando desde la zona de los fieles hubiera una gran continuidad hacia nosotros, pero que de parte de nosotros hacia los fieles hubiera una mayor independencia.

Otro punto importante es el recorrido. Es un tema finamente desarrollado, desde el cerro. El acceso, ¿cómo surgió en el proyecto?

Me gustaba mucho la idea de hacer una entrada dinámica y otra entrada para nosotros como contrapartida. Después, fue saliendo la idea de la rampa (Fig. 4): la clave era producir un acceso dinámico, lo que dio origen a que esto fuera un caminar y no un entrar directo.

Al definirse el camino de acceso por el lado poniente, los fieles entran por el poniente y nosotros por el lado opuesto. La idea era que los fieles continuaran el ascenso del cerro dentro de la arquitectura. Nosotros somos un pueblo peregrino, era importante que esto se acogiera. La rampa tiene el sentido de predisponer el ánimo, que vean que hay un clima distinto y se preparen para lo que encontrarán adentro; una etapa intermedia, que haga consciente el caminar, el silencio; y la Virgen como meta, que recibe, acoge, y dirige hacia el altar mayor (Fig. 4).

\section{LA LUZ}

¿Por qué se eligió la luz como materia fundamental para el proyecto?

La luz tiene un significado esencial en nuestra fe cristiana. Se trataba de crear un espacio de oración y celebración de los misterios cristianos que la liturgia desarrolla. Espacio que no deseábamos abierto al exterior, a pesar de lo atractivo del paisaje, sino vuelto hacia el interior, buscando un recogimiento.

Un espacio cerrado puede llegar a ser claustrofóbico si no se hace presente la luz natural con todos sus matices diarios y de las estaciones anuales. Para nosotros, que consagramos el tiempo juntándonos siete veces al día en la iglesia para cantar los salmos, es vital esta presencia de la luz natural. No podríamos celebrar en un espacio atemporal.

Relacionando la luz con la liturgia, en ciertos momentos se ilumina el altar. ¿Cómo se pensó la luz en ese sentido?

Hay un dinamismo en el ingreso de la luz, que va guiando al fiel hacia el altar. Desde la rampa, con una luz tenue que apunta hacia el lugar de la Virgen, con bastante más luz; la nave de los fieles es más oscura, 

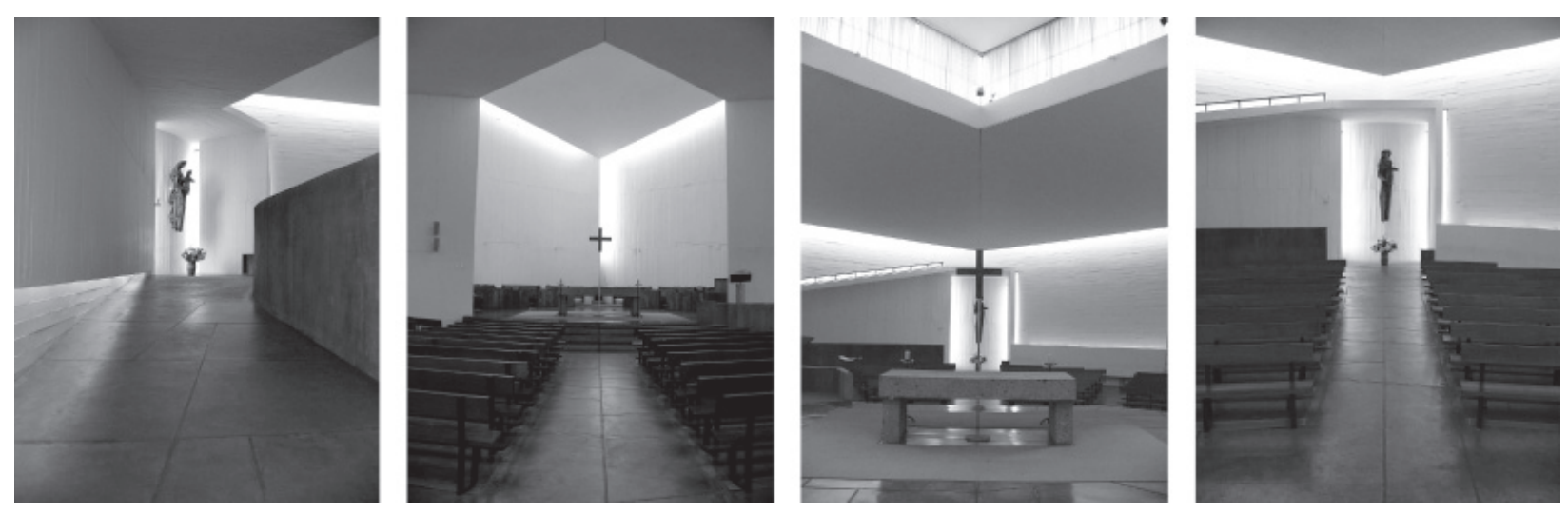

4 (De izda. a dcha.) Martín Correa Prieto y Gabriel Guarda Geywitz, iglesia del monasterio benedictino de Santa María, Las Condes (Chile), 1962/64; acceso por la rampa, vista del presbiterio desde la nave, vista de la nave desde el presbiterio, e imagen de la Virgen.

para rematar en el presbiterio, con el altar plenamente iluminado (Fig. 4). Tratándose de un espacio enclaustrado, la forma en que entra la luz al interior en forma indirecta, reflejada por los muros, hace que estos y el espacio en general sean más etéreos.

Por otra parte, el rajón del fondo es central para tomar el sol de la mañana, el símbolo del Señor (tanto es así que las iglesias antiguas estaban orientadas). Si bien la iglesia no tiene su cabecera orientada hacia el este, como era bastante tradicional, sin embargo la abertura del fondo sí recibe los primeros rayos del sol, símbolo de Jesucristo, llamado sol de justicia por el profeta Malaquías $(3,20)$, "una luz de lo alto, para iluminar a los que viven en tinieblas" (Lc 1,78).

La configuración del altar, el cubo desmaterializado por la luz, se transforma en el equivalente a lo que podría haber sido un retablo o una imagen religiosa. Aqui sería un espacio de luz.

No fue pensado conscientemente en ese sentido. Estábamos preocupados por lograr la continuidad entre los dos cubos, con la convergencia en el altar, reforzada con las líneas del piso. Lo primero que se me ocurrió fue un techo plano, pero en la maqueta, con la altura de la esquina, uno se daba cuenta de que se producía una posibilidad de fuga, quitándole importancia al altar como centro; por eso el cielo baja en el altar.

Desde el ingreso a la iglesia por parte de los fieles, la luz siempre es indirecta. Sin embargo, desde los monjes, las entradas son directas: ¿por qué?
Así como desde los fieles se busca la continuidad del espacio, sin ningún foco que encandile, desde nuestro lado interesaba cortar esta relación con los fieles, que los fieles sean una penumbra y, de hecho, se produce. El sector de los fieles es más oscuro. También hay una serie de elementos, como el altar, los mismos sacerdotes, los celebrantes, que actúan de cortina, produciendo un cubo en sí mismo.

Lo que nos preocupaba era no tener presente un vacío toda la semana, lo que sería desilusionante. Desde nuestro lado el cubo prácticamente se cierra y lo demás se ve en contraste: la luz encandila para no ver más allá (Fig. 4).

El espacio del altar, un cubo de luz inasible, casi toma un rol simbólico abstracto, queriendo significar algo.

Eso ya entra en el eco de lo que está en cada uno. En todo caso, no había la menor intención de producir algo atractivo. Se pretendía que el templo fuera lo menos presente, lo menos insistente, anónimo, de modo que no llamara la atención; por eso es blanco, son matices de blanco... La idea no es que alguien venga a la iglesia a mirarla: viene a ponerse en situación de orar, la idea es resaltar la liturgia, lo que se realiza, el acto litúrgico (Fig. 5).

La iglesia de Las Condes es un caso ejemplar en la instrumentalización de la luz como materia central del proyecto arquitectónico, destacándose su exacta medida con respecto al acto litúrgico. Si bien Martín Correa plantea cómo se buscaba llevar a su esplendor 
el acto litúrgico, con una arquitectura que pasase a segundo plano, que fuera "lo menos presente", pasando desapercibida, la calidad de su luz constituida como generatriz de la forma cúbica, con sus sutiles variaciones temporales, hacen que esta obra alcance una calidad estética, que ineludiblemente invita a su contemplación. Con una ausencia en su percepción formal solo relativa, sin dejar por ello de realzar la liturgia —el prima principio del edificio iglesia—, da cuenta al mismo tiempo de una concepción simbólica, moviéndose con acierto en el límite entre la ausencia y la presencia, entre la abstracción y la representación, entre la modernidad y la tradición.

Es así como, junto con dar respuesta a los requerimientos funcionales del rito, buscando un espacio que predisponga a "una posición para orar", se logran hacer presentes de forma sensible los misterios celebrados, recogiendo de forma contemporánea las tradicionales formas de mediación con lo sagrado: el rito y el símbolo.

\section{Notas}

1. Declaraciones personales de Alberto Cruz Covarrubias al autor (Santiago de Chile, 6 de diciembre de 2008). En 1952, Alberto Cruz (Premio Nacional de Arquitectura 1975), encabezó un grupo de arquitectos y artistas - Fabio Cruz Prieto, Miguel Eyquem Astorga, José Vial Armstrong, Arturo Baeza Donoso, Jaime Bellalta Bravo, Godofredo Iommi Marini (poeta), Francisco Méndez Labbé (pintor) y Claudio Girola Iommi (escultor, miembro fundador de la Asociación de Arte Concreto en Argentina) - que refundaron la Escuela de Arquitectura de la Universidad Católica de Valparaíso, creando simultáneamente el Instituto de Arquitectura. Durante las décadas de los 50 y 60, dicho Instituto propuso una instancia de investigación proyectual iniciada con el proyecto fundacional de la capilla de Pajaritos, desarrollando una investigación sobre arquitectura sacra que se concretaría, entre otras propuestas, en la reconstrucción post-terremoto de las iglesias del sur. Dicho grupo formuló un planteamiento original acerca de la concepción del oficio de la arquitectura, destacándose la concepción poética de Amereida realizando una travesía épica por el continente americano (1964), la concepción arquitectónica de la Ciudad Abierta fundada en Ritoque en 1970, y las Travesías por América, que se incluyeron en el plan de estudios a partir de 1980 .

2. Martín Correa Prieto nace en Santiago de Chile (1928). Estudia arquitectura en la PUC de Santiago de Chile, licenciándose en 1952 y decidiendo de forma voluntaria no titularse como arquitecto (no realizó el PFC) para ingresar a la vida monástica. En su formación, destaca de forma especial la influencia de Alberto Cruz Covarrubias (fundador de la PUCV), quien impartía la cátedra de Plástica y promovió un profundo cambio en la enseńanza, dejando de lado la enseñanza clásica centrada en el Vignola para incorporar un sistema moderno de fuerte inspiración en los postulados de la Bauhaus. Después de esta iglesia no realizó más obras, si bien dirigió una fábrica de muebles en el mismo monasterio. Hasta el día de hoy, sigue explorando el espacio a través de la escultura, declarándose cercano a la obra de Chillida.

Por su parte, Gabriel Guarda Geywitz nació en Valdivia (1928). Monje benedictino y presbítero, es arquitecto por la PUC de Santiago de Chile (1958), destacando de su formación la importancia de la enseńanza clásica previa a la reforma moderna. Estudió Historia en la Facultad de Filosofía y Letras de la Universidad Central en Madrid (hoy Universidad Politécnica), en la Universidad Internacional Menéndez y Pelayo, en Santander, y en la Escuela de Estudios Hispanoamericanos de la Universidad de Sevilla. Connotado investigador, ha recibido el Premio Nacional de Historia en 1984. Actualmente es consultor de la Unesco y desde el año 2001, presidente de la Comisión de Bienes Culturales de la Iglesia católica en Chile. También ha sido galardonado con el Premio Bicentenario (2003), en reconocimiento a su extenso trabajo sobre el patrimonio arquitectónico en Chile.

3. "La iglesia del Monasterio Benedictino de la Santísima Trinidad de Las Condes. La luz como generatriz del espacio moderno litúrgico", dirigida por Víctor Pérez Escolano en el Departamento de Historia, Teoría y Composición Arquitectónicas, ETSA de la Universidad de Sevilla (España).

4. Jaime Bellalta Bravo nació en Santiago de Chile (1922), titulándose de arquitecto por la PUC de la misma ciudad (1949). Realizó estudios de posgrado con Walter Gropius en Harvard, y a su regreso a Chile se trasladó a Valparaíso, siendo uno de los fundadores de la PUCV (1952). Estando allí asumió la invitación para participar en el concurso del monasterio, concurso que ganó en 1953 y desarrolló en Santiago de Chile, distanciándose de la Escuela de Valparaíso. Posteriormente viajó a Inglaterra, estableciéndose finalmente en EEUU, donde se desempeñó como docente en la University of Notre Dame, en Indiana.

5. Tema desarrollado en Rubén Muñoz Rodríguez, "La iglesia del Monasterio Benedictino de la Santísima Trinidad de Las Condes. Propuestas precedentes", arquitetura revista, 6 (2010): 106-126. Doi: 10.4013/arq.2010.62.03.

6. Humberto Eliash Díaz y Manuel Moreno Guerrero, Arquitectura y modernidad en Chile, 1925-1965. Una realidad múltiple (Santiago de Chile: UC, 1989), 68.

7. Cf. Fernando Pérez Oyarzun et al., "El espacio sagrado como reto de la arquitectura moderna. De la capilla de Pajaritos al Monasterio Benedictino", ARQ 30 (1995): 4-13.

8. Cf. Alberto Cruz Covarrubias, "Proyecto Achupallas y capilla Pajaritos", en Anales de la Universidad Católica de Valparaíso (Valparaíso: UCV, 1954), $235-242$.

9. Cf. declaraciones personales de Gabriel Guarda Geywitz al autor (Santiago de Chile, 29 de agosto de 2007). Inéditas.

10. El monasterio de Las Condes mantuvo una estrecha relación con los planteamientos desarrollados en los principales centros donde se desarrolló el Movimiento Litúrgico previo al Concilio Vaticano II. Junto con el monasterio alemán de Beuron — de donde es originario el monasterio de Las Condes_- cabe nombrar los de María Laach, Santa Hildegarda — donde fue capellán Odo Casel_ y Monserrat, siendo todos ellos importantes centros de estudio y experimentación litúrgica pertenecientes al monacato benedictino.

11. Cf. Concilio Vaticano II, Constitución Sacrosanctum Concilium sobre Sagrada Liturgia (Madrid: Biblioteca de Autores Cristianos, 1973 ), 239.

\section{Procedencia de las ilustraciones}

Fig. 01. Alberto Cruz Covarrubias, "Proyecto Achupallas y capilla Pajaritos”, en Anales de la Universidad Católica de Valparaíso (Valparaíso: UCV, 1954). Fig. 02. Jaime Bellalta Bravo, Proposición. Convento Benedictinos (Valparaíso: Archivo Histórico José Vial/PUCV, 1953).

Fig. 03. Planta: Patricio Gross Fuentes y Enrique Vial Briceńo, El monasterio benedictino de las Condes (Santiago de Chile: PUC, 1988). Isométrica exterior: Fernando Pérez Oyarzun et al., Iglesias de la modernidad en Chile (Santiago de Chile: ARQ, 1997). Isométrica interior: Wren Strabucchi (ed.), Cien años de arquitectura en la Universidad Católica (Santiago de Chile: ARQ, 1994).

Fig. 04-05. Archivo del autor (2009 y 2011). 


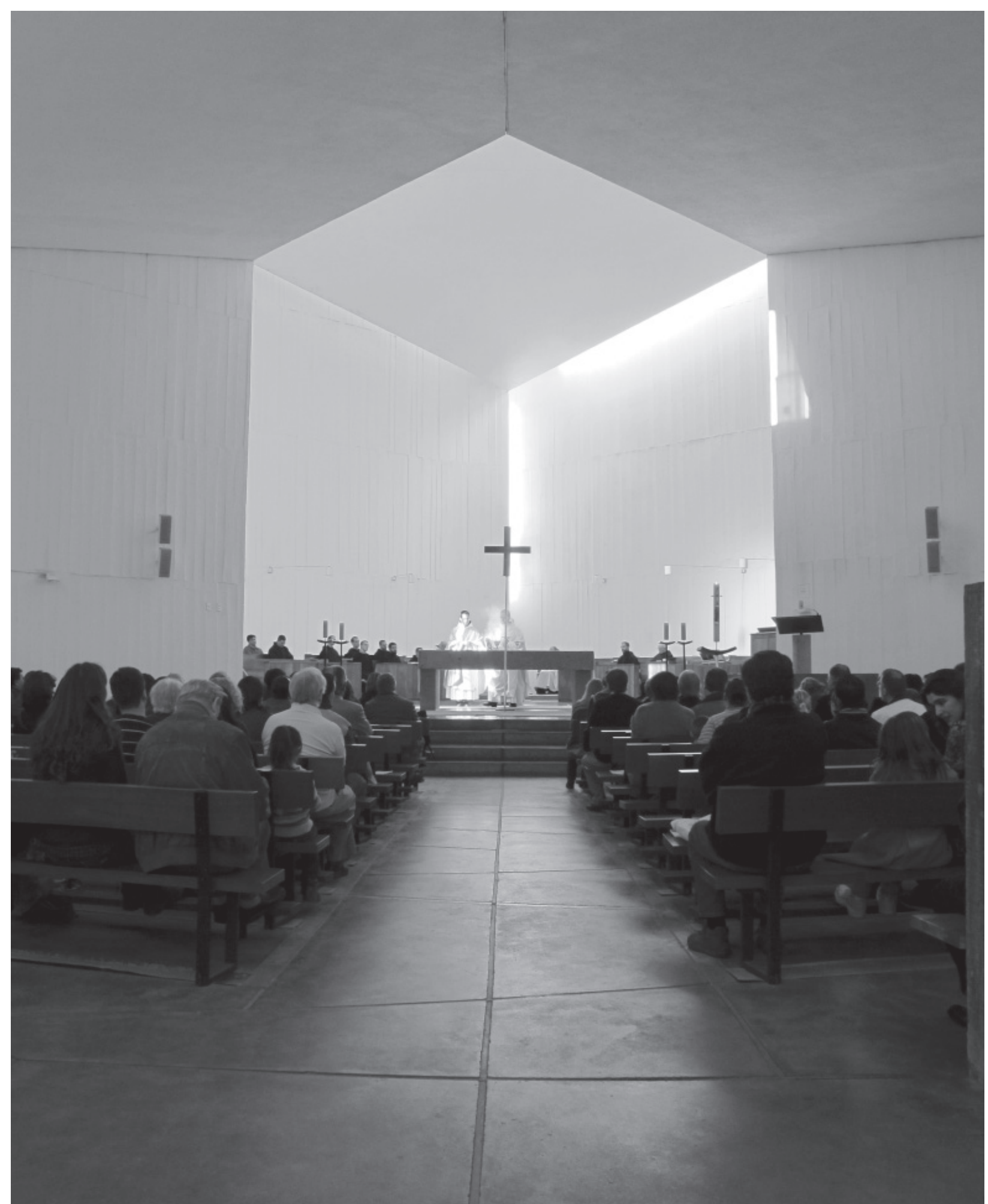

5 Iglesia del monasterio benedictino de Santa María, Las Condes; el espacio celebrativo.

\section{Sobre el autor}

Rubén Muñoz Rodríguez (Barcelona, 1973). Arquitecto (Universidad del Bío Bío, Concepción, Chile, 2000. Premios: “Escuela de arquitectura UBB” y "Arquitecto Rodolfo Oyarzun Philippi"). DEA (2009) en Arquitectura por la ETSA de la Universidad de Sevilla, Espańa, con la tesis doctoral en curso: "La iglesia del Monasterio Benedictino de la Santísima Trinidad de Las Condes. La luz como generatriz del espacio moderno litúrgico". Profesor de Proyectos y Composición en la FACD de la Universidad del Bío Bío, Concepción, Chile, desde 2005, año en el que funda su propio estudio de arquitectura. Ha realizado diversas ponencias y proyectos sobre arquitectura sacra, colaborando con el Consejo Arquidiocesano de Arquitectura y Arte Sagrado del Arzobispado de Concepción, Chile.

rmunozro@ubiobio.cl 